\title{
Granulomatous Prostatitis: Case Report and Review of the Literature
}

\author{
(1) Meriç Doğan Güven MD, (1) Taha Numan Yıkılmaz MD, (1) Erdem Öztürk MD, (1) Halil Başar MD \\ University of Health Sciences, Dr. Abdurrahman Yurtaslan Ankara Onkoloji Training and Research Hospital, Clinic of Urology, Ankara, Turkey
}

\begin{abstract}
Granulomatous prostatitis, first described by Tanner and McDonald in 1943, is a histopathological diagnosis that includes mixed type inflammation with granulomas in the prostatic tissue. Granulomatous prostatitis comprises $0.8-1 \%$ of benign inflammatory conditions of the prostate. Prior surgery, intravesical bacillus Calmette-Guérin treatment, or systematic tuberculosis are some causes of granulomatous prostatitis. It mimics prostate cancer clinically, histologically, and biochemically. Granulomatous prostatitis has a specific and nonspecific type, with the nonspecific type being more common. In this study, we report a patient who had high prostate-specific antigen level and underwent transrectal ultrasound-guided prostate biopsy, and histologic examination revealed nonspecific granulomatous prostatitis.
\end{abstract}

Keywords: Granulomatous prostatitis, prostate-specific antigen, prostatitis

\section{Introduction}

Urinary tract infections, benign prostatic hyperplasia, and stone diseases are among the most common pathologies of the urinary system. Prostatitis accounts for $10-14 \%$ of urinary tract infections. Unlike the more common acute bacterial prostatitis (98-99\%), chronic bacterial prostatitis, chronic pelvic pain syndrome, and asymptomatic prostatitis, granulomatous prostatitis (GP) accounts for less than 1\% of all cases of prostatitis and its etiology is unknown. GP can often be seen after surgical interventions and intravesical bacillus Calmette-Guérin (BCG) therapy. In this study, we present a case of GP detected in a patient who underwent transrectal ultrasound (TRUS)-guided prostate biopsy for suspected prostate cancer after testing revealed elevated serum prostate-specific antigen (PSA) level.

\section{Case Presentation}

A 63-year-old male patient presented to our clinic with complaints of dysuria, pollakiuria, and nocturia. He had no history of treatment for prostate infection or prior prostate or bladder surgery. On physical examination, digital rectal examination was normal, there were no signs of suprapubic tenderness, and systemic examination was normal. Routine blood and urine analysis showed serum PSA level of $9.32 \mathrm{ng} / \mathrm{mL}$ and free PSA level of $0.907 \mathrm{ng} / \mathrm{mL}$. Urinalysis was normal. Based on these findings, TRUS-guided prostate biopsy was performed due to suspected prostate cancer. Biopsy results indicated nonnecrotizing GP. The patient was followed in our clinic to monitor his serum PSA level. Three months later, his serum PSA level was $8.4 \mathrm{ng} / \mathrm{mL}$.

The patient provided informed consent for this case report.

\section{Discussion}

GP, which was first described by Tanner and McDonald (1) in 1943 , is a histopathological diagnosis characterized by mixedtype inflammatory granulomas of the prostate. GP can be bacterial, fungal, parasitic, or viral and the mixed inflammation includes histiocytes, lymphocytes, and plasma cells. Pathologic examination in our case revealed well-defined granulomatous 
structures containing a central giant cell surrounded by lymphoplasmacytic cells (Figures 1A, B).

GP comprises $0.8-1 \%$ of benign inflammatory prostate disease. The nonspecific GP is the most common type, accounting for $77 \%$ all cases. Clinically, 59\% of cases present with prostate lumps or hardness, mimicking prostate cancer (2). PSA levels may be normal or elevated. Histopathologically, $4 \%$ of nonspecific cases mimic prostate cancer with high Gleason grade (3).
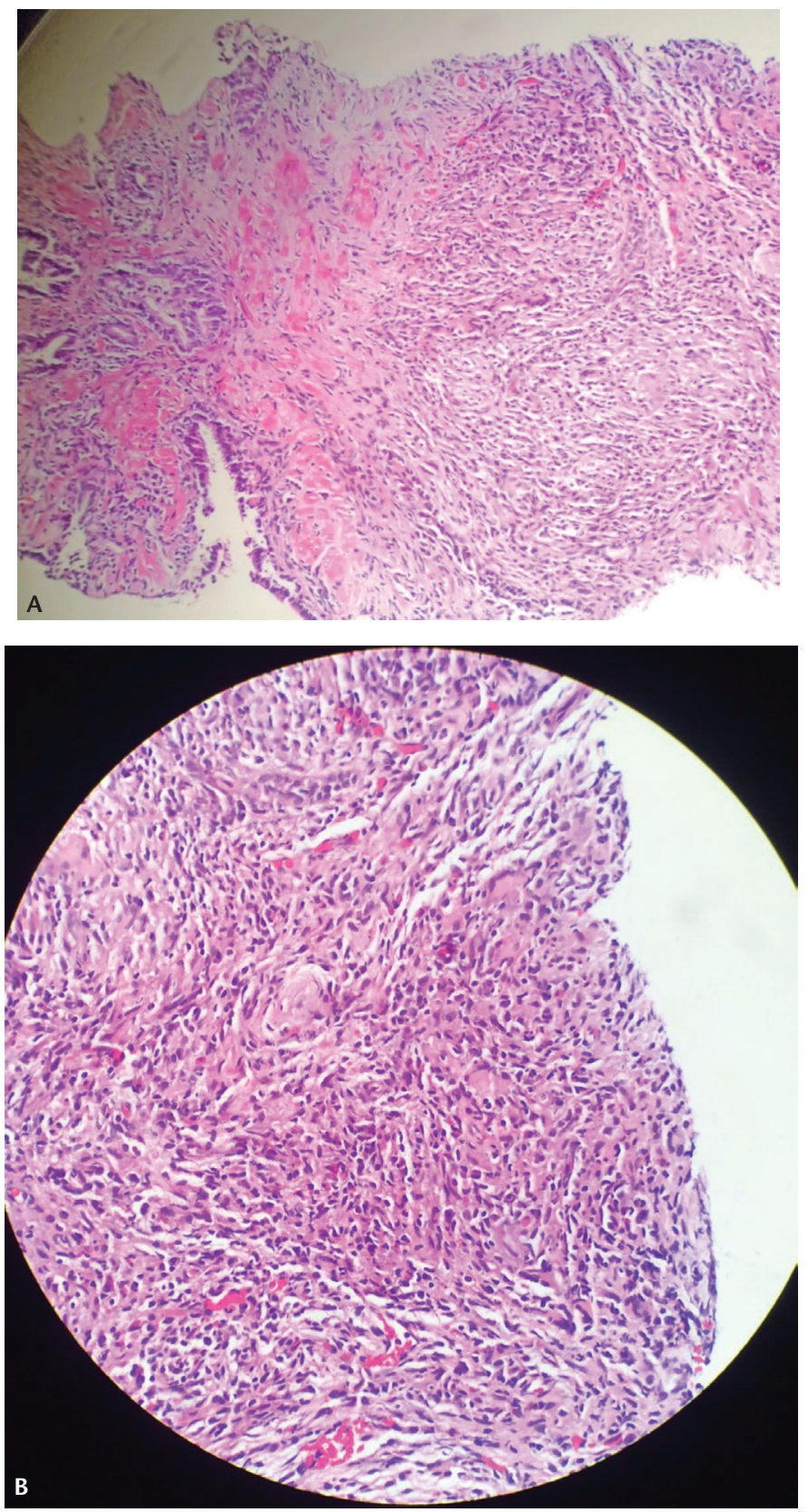

Figures $1 \mathrm{~A}, \mathrm{~B}$. In the examined sections, giant glandular structures lined with 2 rows of epithelium and large and small granulomatous structures consisting of histiocyte clusters with multinuclear giant cells which in some areas replace the gland are observed in the fibromuscular stroma
Concomitant prostate cancer was not observed in our patient during follow-up. Although the etiopathogenesis of the disease remains unclear, urinary infections, surgical interventions involving the prostate, and intravesical BCG therapy have been implicated in the etiology. In 1981, Hedelin et al. (4) first described GP in 6 patients who underwent transurethral prostate resection (TURP). In 1986, Helpap and Vogel (5) reported that they detected GP in $7.1 \%$ of 2850 prostate specimens examined. They suggested that electrocautery was the causative factor of GP, as in previous experimental studies. While GP after TURP was reported as rheumatoid granulomas in pathologic examination, GP after BCG presents as tuberculous granulomas. Leibovici et al. (6) observed serum PSA levels in $75 \%$ of 36 patients after intravesical chemotherapy treatment and therefore associated it with GP.

GP can occur after both intravesical and systemic BCG administration. In a study evaluating radical prostatectomy specimens, the incidence of GP in BCG patients was $1-27 \%$ (7). Another cause of GP is the injection of Teflon material into the bladder neck as treatment for urinary incontinence. It has been reported that nonspecific GP develops as an autoimmune reaction via human leukocyte antigen-15-mediated $T$ cell response to certain proteins, particularly those found in prostate secretions such as PSA (8). It is also proposed that GP may be an autoimmune disease. Rarely, GP can coexist with systemic granulomatous diseases such as Wegener's granulomatosis. Nonetheless, it is referred to as nonspecific GP because a specific cause cannot be determined in the majority of patients, similar to our case.

In various series, GP has been reported in $0.36-11 \%$ of patients after TRUS-guided biopsy for suspected prostate cancer. Herranz et al. (9) reported detecting GP at a rate of $1.5 \%$ after TRUS-guided biopsy in 1835 patients. It has been proposed that prostate secretions due to the biopsy procedure and substances secreted by various bacterial agents have a role in the etiology of GP in cases of nonspecific prostatitis after TRUS-guided biopsy. Patients with GP may present with storage and voiding symptoms or complaints of pelvic pain, or they may be asymptomatic. As in the present case, this pathology may also manifest with normal digital rectal examinations but elevated PSA levels. For this reason, GP can mimic prostate cancer clinically and histologically. However, this increase in PSA level is usually transient and associated with other factors such as infection, retention, and diagnostic interventions. Because most cases are nonspecific, they regress spontaneously without requiring treatment. In some studies, however, antibiotic and cortisone therapy was reported to dramatically improve symptoms and lower serum PSA to normal levels. Therefore, although rare, GP should be considered in patients with elevated serum PSA or who exhibit serum PSA elevation after TRUS-guided biopsy.

\section{Ethics}

Informed Consent: The patient provided informed consent for this case report.

Peer-review: Internally peer-reviewed. 


\section{Authorship Contributions}

Surgical and Medical Practices: M.D.G., Concept: T.N.Y., E.Ö., Design: E.Ö., Data Collection or Processing: M.D.G., T.N.Y., Analysis or Interpretation: H.B., Literature Search: M.D.G., T.N.Y., Writing: M.D.G.

Conflict of Interest: No conflict of interest was declared by the authors.

Financial Disclosure: The authors declared that this study received no financial support.

\section{References}

1. Tanner FH, McDonald JR. Granulomatous prostatitis: a histologic study of a group of granuloma-tous lesions collected from prostate glands. Arch Pathol Lab Med 1943;36:358-370.

2. Presti B, Weidner N. Granulomatous prostatitis and poorly differentiated prostate carcinoma. Their distinction with the use of immunohistochemical methods. Am J Clin Pathol 1991;95:330-334
3. Val-Bernal JF, Zaldumbide L, Garijo MF, González-Vela MC. Nonspecific (idiopathic) granuloma-tous prostatitis associated with low-grade prostatic adenocarcinoma. Ann Diagn Pathol 2004;8:242-246.

4. Hedelin $\mathrm{H}$, Johansson $\mathrm{S}$, Nilsson S. Focal prostatic granulomas. A sequel to transurethral resection. Scand J Urol Nephrol 1981;15:193-196.

5. Helpap B, Vogel J. TUR-prostatitis. Histological and immunohistochemical observations on a special type of granulomatous prostatitis. Pathol Res Pract 1986;181:301-307.

6. Leibovici D, Zisman A, Chen-Levyi Z, et al. Elevated prostate specific antigen serum levels after intravesical instillation of bacillus CalmetteGuerin. J Urol 2000;164:1546-1549.

7. Rischmann P, Desgrandchamps F, Malavaud B, Chopin DK. BCG intravesical instillations: re-commendations for side-effects management. Eur Urol 2000;37(Suppl 1):33-36.

8. Alexander RB, Mann DL, Borkowski AA, et al. Granulomatous prostatitis linked to HLA-DRB1*1501. J Urol 2004;171:2326-2329.

9. Herranz Amo F, Verdú Tartajo F, Díez Cordero JM, et al. [Non-specific granulomatous prostatitis diagnosed with ultrasonography-guided transrectal biopsy]. Actas Urol Esp 1998;22:757-761. 